\title{
SUBSIDENCE EVALUATION OF HIGH-SPEED RAILWAY IN SHENYANG BASED ON TIME-SERIES INSAR
}

\author{
Y. Zhang, L. Wei*, J. Li, S. Liu, Y. Mao, L. Wu \\ School of Resources and Civil Engineering, Northeastern University, 110004 Shenyang, China - weilianhuan@mail.neu.edu.cn
}

\author{
Commission VI, WG III/3
}

KEY WORDS: High-speed Railway, Subsidence, Time-series InSAR

\begin{abstract}
:
More and more high-speed railway are under construction in China. The slow settlement along high-speed railway tracks and newlybuilt stations would lead to inhomogeneous deformation of local area, and the accumulation may be a threat to the safe operation of high-speed rail system. In this paper, surface deformation of the newly-built high-speed railway station as well as the railway lines in Shenyang region will be retrieved by time series InSAR analysis using multi-orbit COSMO-SkyMed images. This paper focuses on the non-uniform subsidence caused by the changing of local environment along the railway. The accuracy of the settlement results can be verified by cross validation of the results obtained from two different orbits during the same period.
\end{abstract}

* Corresponding author

\section{INTRODUTION}

In recent years, China has ushered a new era with a lot of highspeed railway infrastructure construction, indicating the rapid economic development of the whole country. The pressure on the roadbed and elevated bridges of high-speed railway is much higher than traditional rail tracks because of the extremely high speed. The slow settlement along and around the high-speed rail tracks may also threaten the safe operation of high-speed trains after a long period of accumulation. Besides, newly-built highspeed railway stations may also lead to inhomogeneous deformation of the surrounding area. Therefore, continuously monitoring the settlement of high speed rail tracks and stations is a key to ensure the safety and long-term development of public transportation safety (Dai, 2013; Liu, 2016; Shi, 2015; Yang, 2015).

\section{DEFORMATION MONITORING WITH TIME SERIES INSAR}

Time-series InSAR utilizes stable points which are not influenced by saptial-temporal decorrelation and suppresses the atmospheric delaying phase. The evolution of surface deformation is obtained by separating the atmospheric phase and deformation phase in time series based on their different spatial-temporal characteristics. In our data processing, interferograms are firstly generated after selection of a common master, image coregistration and resampling of slave images. Secondly, the phase variation caused by flat earth with reference to the ellipsoid is estimated and removed, followed by geocoding of the flattened interferograms. Then, amplitude and phase analysis are conducted to estimate the probability of individual pixels as PS candidates, resulting in a subset of PS candidates. Next, the selected PS candidates are filtered to reject those that appear to be persistent accidentally which are dominated by scatterers in adjacent PS pixels or are only persistent in certain interferograms. For each PS point, the wrapped phases in differential interferograms can be decomposed into uncompensated topography, motion of the target between different acquisitions, the object scattering phase related to the path length traveled in the resolution cell, atmospheric phase delays, the phase caused by imprecise orbit data, and additive noise. Finally, the phases are unwrapped and the unwrapped phases are divided into DEM error phase, deformation phase, atmospheric phase screen (APS) distribution of master and slave images and noise (Balz, 2012; Ferretti, 2001; Hooper, 2006; Pigorini, 2010).

\section{RESULT ANALYSIS}

Due to the stable backscattering, high-speed rail tracks and stations maintain good coherence over a long time span (Qin, 2016; Chang, 2017 ), which can provide a large amount of point scatterers for subsidence monitoring. With Time series InSAR technology, the inherent constraints of decorrelation and atmospheric artifacts are properly handled, signals with different spatio-temporal attributes are separated, resulting in reliable surface deformation results. The data used in this article are $18 \mathrm{X}$-band SAR images acquired from two different orbits by the Italian COSMO-SkyMed constellation from 2016.3 to 2016.10. The coverage of CSK images is shown in Figure.1. Our study area, the Shenyang South station high-speed railway, is highlighted with red lines in the overlap area of two different orbits.

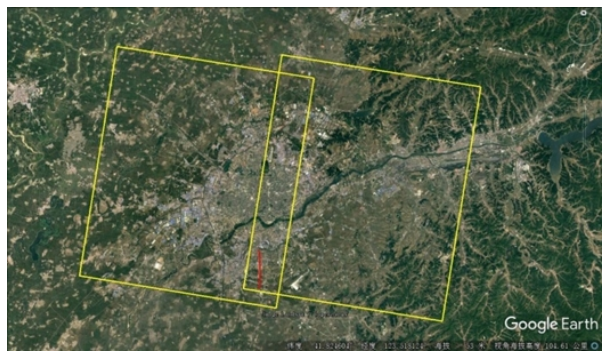

Figure 1.Coverage of the CSK images(yellow rectangle) 
With the use of high-resolution COSMO-SkyMed images, good measurement of the deformation along the rail track and station is revealed. A very high sensitivity to deformation is expected as well because of the short wavelength of X-band data.

The overall deformation pattern of two different orbits in highspeed railway near Shenyang South Railway Station is depicted in Figure.2(a) and Figure.2(b). The red and blue dots shown in Fig.2 represent subsidence and raise respectively, the settlement increases with the red color deepening and decreases with the blue color deepening. The deformation rate is annotated in the lower right corner of the Figure 2. Since the time span of the two different stacks are briefly the same, therefore similar subsidence pattern are detected from both stacks.

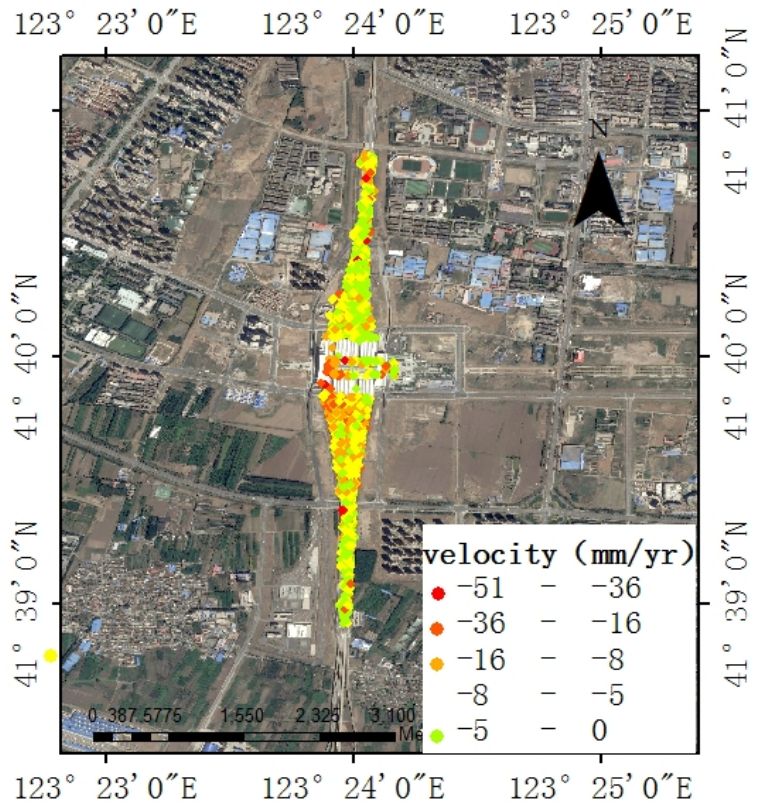

Figure.2(a) Overall deformation pattern from the western stack

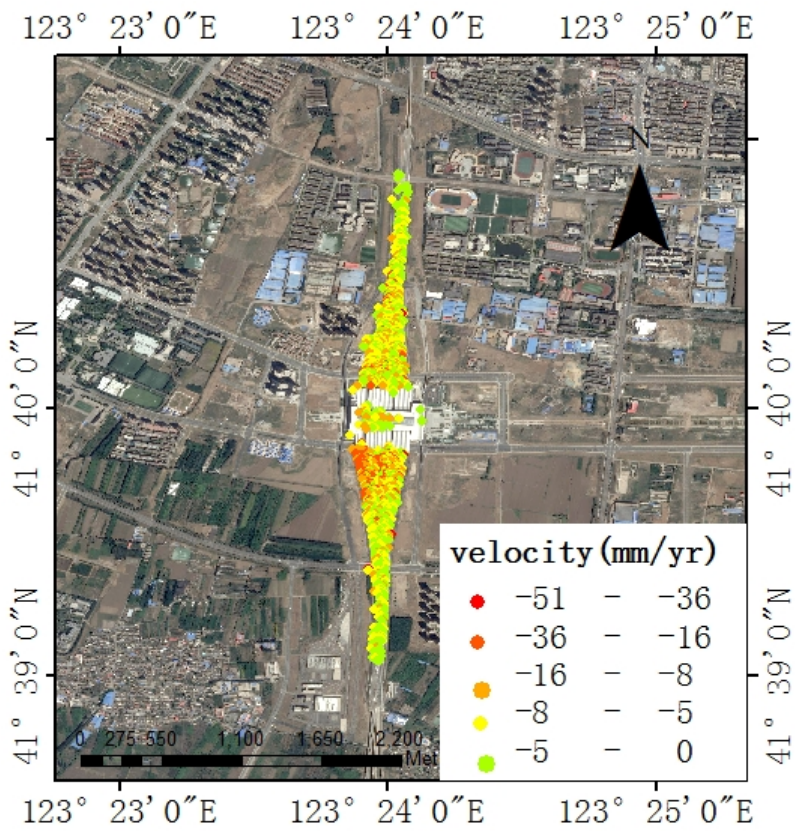

Figure.2(b) Overall deformation pattern from the eastern stack

As shown in Fig.2, the largest deformation happens on the rail tracks near the southern part of the platform. In order to further investigate the scale of the deformation, the authors made a brief statistics of those PS points. As shown in Table.1, most points have a deformation rate below $16 \mathrm{~mm} / \mathrm{yr}$, which seem to be quite stable. This is because the construction of Shenyang South Railway Station was completed in 2015.8, the accumulation of deformation should have slowed down during the time span of our monitoring.

\begin{tabular}{|c|c|c|}
\hline $\begin{array}{c}\text { Velocity } \\
(\mathrm{mm} / \mathrm{yr})\end{array}$ & $\begin{array}{c}\text { Number of PS } \\
\text { points on the east }\end{array}$ & $\begin{array}{c}\text { Number of PS } \\
\text { points on the West }\end{array}$ \\
\hline$-51--36$ & 5 & 11 \\
$-36--16$ & 73 & 77 \\
$-16--8$ & 573 & 690 \\
$-8--5$ & 450 & 413 \\
$-5-0$ & 432 & 406 \\
\hline
\end{tabular}

Table.1 Statistics of PS points

In the analysis, points with severe subsidence are further investigated by cross-validation of the results from both stacks. As shown in Figure.2(a) and Figure.2(b), the rail tracks to the south of Shenyang South Railway Station suffer from severe settlement. The deformation pattern of this specific area is cross analyzed with results from both stacks.

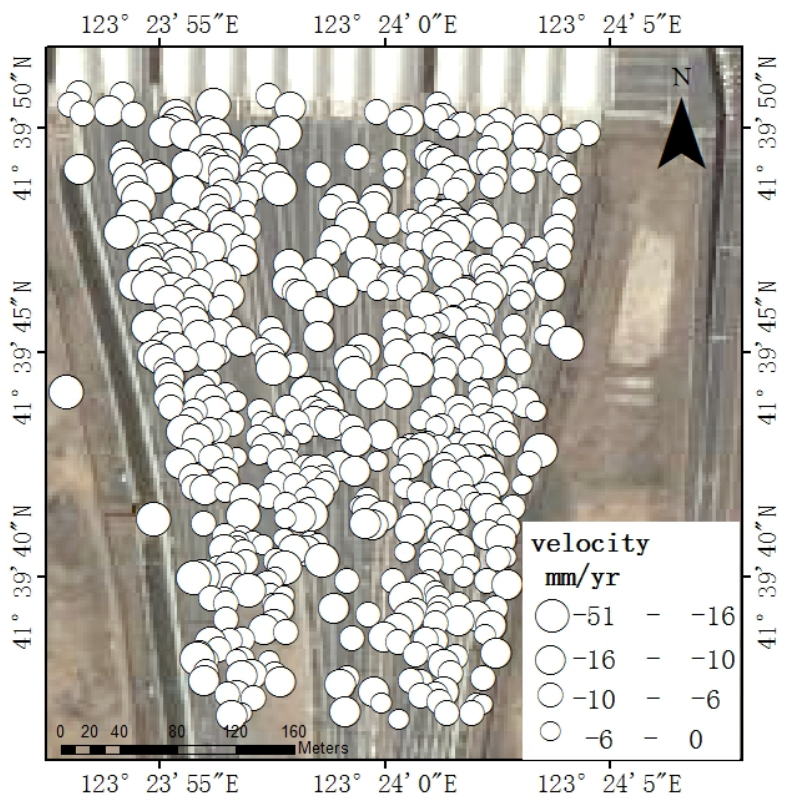

Figure.3(a) Subsidence pattern to the south of Shenyang South Railway Station in the western stack

As shown in Figure.3(a) and Figure.3(b), the subsidence pattern in the western and eastern stacks is depicted. Each PS point is represented with a circle and the size of each circle indicates its deformation rate. The larger the size, the larger the deformation rate. The subsidence rate of the western side near the shelter is the largest, the velocities varies from $-51 \mathrm{~mm} / \mathrm{yr}$ to $-16 \mathrm{~mm} / \mathrm{yr}$. While, the deformation of other parts in our study area is smaller, with deformation rate varying from $-16 \mathrm{~mm} / \mathrm{yr}$ to $0 \mathrm{~mm} / \mathrm{yr}$ 


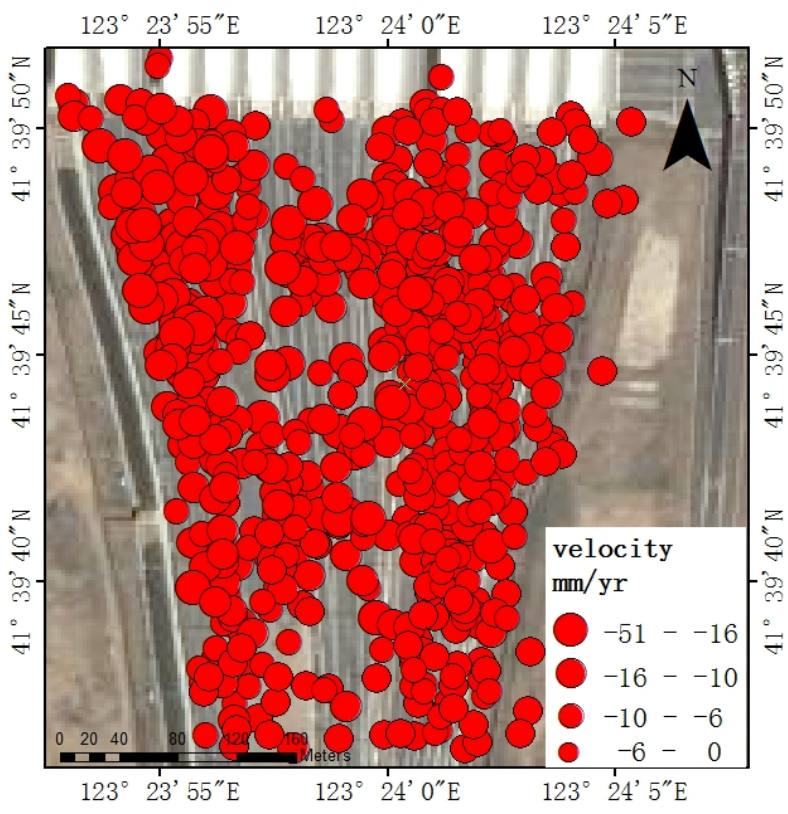

Figure.3(b) Subsidence pattern to the south of Shenyang South Railway Station in the eastern stack

In order to fully understand the deformation pattern of different rail tracks near the station, the deformation profile of points along latitude 42.6633 are depicted. As shown in Fig.4, this profile is located to the south of Shenyang South Railway Station (marked as green line). The deformation rates along this profile in both stacks are plotted in Fig.5. According to the deformation profile, the rail tracks show different subsidence. Besides, the largest settlement occurs in the middle and east part. The results from both orbits present identical subsidence patterns along this profile.

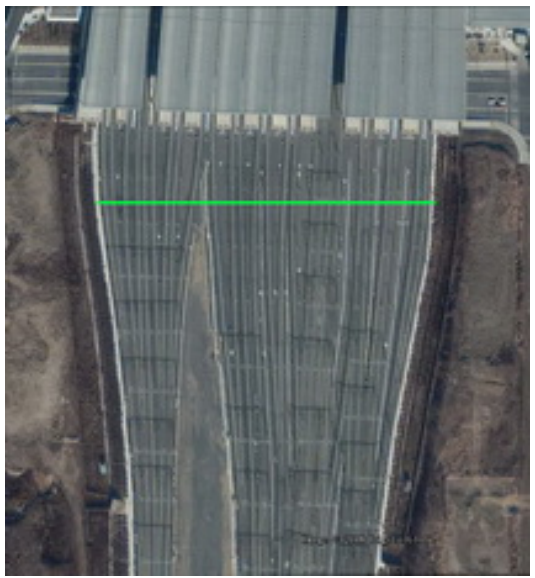

Figure.4 Location of the elevation profile in Google-earth

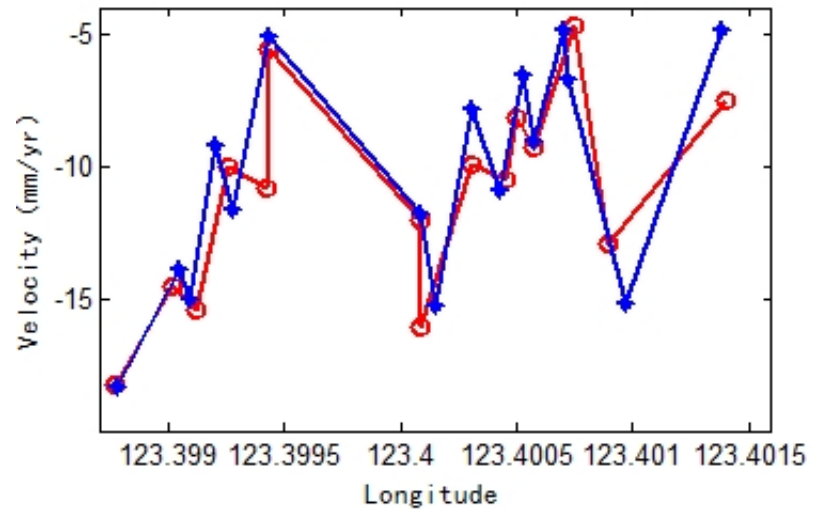

Figure.5 Cross-section(latitude 42.6633)

\section{CONCLUSIONS}

In this paper, the uneven subsidence of the newly-built Shenyang South Railway Station and the nearby high-speed railway line is retrieved by time series InSAR analysis with COSMO-SkyMed images acquired from two different orbits. The accuracy of our experimental result is guaranteed by the cross-validation of two different orbits, which show very good consistency. The results in this paper have demonstrated the great potential of time series InSAR in infrastructure monitoring, especially with the use of multi-orbit data.

\section{ACKNOWLEDGEMENTS}

This work is financially supported in part by the National Natural Science Foundation of China (Grant No. 41601378,41601476 ) and the Fundamental Research Funds for the Central Universities (Grant No. N150103001). The COSMO-SkyMed data is provided by ASI via the ASI-ESA Dragon4 Project ID. 32365_4.

\section{REFERENCES}

Balz T., Wei L., Jendryke M., et al, 2012. Tomosar and PSInSAR analysis of high-rise buildings in Berlin, IEEE Geoscience and Remote Sensing Symposium, pp.447-450.

Chang L., Dollevoet R. P. B. J., Hanssen R. F., 2017. Nationwide Railway Monitoring Using Satellite SAR Interferometry. IEEE Journal of Selected Topics in Applied Earth Observations \& Remote Sensing, vol.(99), pp.1-9.

Dai K., Liu G., Yu B., et al, 2013. Detecting subsidence along a High Speed Railway by ultrashort baseline TCP-InSAR with high resolution images. Isprs Conference on "serving Society with Geoinformatics. pp.61-65.

Ferretti A., Prati C., Rocca F., 2001. Permanent scatterers in SAR interferometry. IEEE Transactions on Geoscience \& Remote Sensing,vol.39(1), pp.8-20.

Hooper A. J., 2006. Persistent scatter radar interferometry for crustal deformation studies and modeling of volcanic deformation. Harvard University. 
Liu X., Song W., Yonghong Z., et al, 2016. Measuring subsidence of transport infrastructure with high resolution PSInSAR. Science of Surveying \& Mapping.

Pigorini A., Ricci M., Sciotti A., et al, 2010. Satellite remotesensing PSInSAR technique applied to design and construction of railway infrastructure. Ingegneria Ferroviaria, vol. 65(9), pp.729-757.

Qin X., Liao M., Shi X., et al, 2016. Stability assessment of high-speed railway using advanced InSAR technique. IEEE Geoscience and Remote Sensing Symposium, pp.6010-6013.

Shi X., Zhang L., Balz T., et al, 2015. Landslide deformation monitoring using point-like target offset tracking with multimode high-resolution TerraSAR-X data. Isprs Journal of Photogrammetry \& Remote Sensing, vol.105, pp.128-140.

Yang Z., Schmid F., Roberts C., 2015. Assessment of railway performance by monitoring land subsidence. IET Railway Condition Monitoring, pp.1-6. 